\title{
REVIEW \\ Development and Diffusion Strategies of Agricultural Production History Management Systems
}

\author{
Atsushi ITOH* \\ Large-scale Farming Research Division, Hokkaido Agricultural Research Center, National \\ Agriculture and Food Research Organization (HARC/NARO) (Kasai, Hokkaido 082-0081, JAPAN)
}

\begin{abstract}
Incidents and accidents involving food items occur frequently, which is why consumers put high emphasis on the safety of food products. Farmers must manage the crop production process efficiently and maintain records related to food safety. This kind of paperwork places a heavy burden on farmers. Therefore, we developed a system utilizing Information and Communication Technology (ICT) that can help farmers easily and efficiently manage the agricultural production process. In Japan, the average age of farmers is more than 65 years old, and their IT literacy is lower compared to the workforce in other industries. Therefore, a system that requires the use of IT devices is not likely to penetrate the agricultural sector. We have developed a system for managing the agricultural production process that allows every farmer to use IT equipment without any problems; the design of the system takes into account both users and non-users of IT equipment. By conducting demonstration experiments, we confirmed that all farmers could use our system. Moreover, enhancing the system's maintainability and scalability by utilizing web application programming interface (Web API) design allows our system to be interoperable with other systems, and helps highlight the potential of our system to become a comprehensive platform for agricultural information in the future.
\end{abstract}

Discipline: Information technology

Additional key words: production process management, IT literacy, cloud service, Web API

\section{Introduction}

Japan's food self-sufficiency ratio based on calories was estimated at approximately 39\% (Ministry of Agriculture, Forestry and Fisheries, 2014). This implies that Japan's agricultural production base is very fragile. With food-related accidents occurring in numerous countries including Japan, such accidents have recently been featured in headlines around the world. For example, a serious incident occurred in Japan in 2002 involving the sale of agricultural products containing hazardous agricultural chemicals (Ministry of Agriculture, Forestry and Fisheries, 2002). Since then, consumers have become much more aware about the safety of their food.

The revision of the Agricultural Chemicals Regulation Law and the Food Sanitation Act has also obligated both people and organizations engaged in farming to manage production processes more strictly at farming sites. And such producer groups as the Japan Agricultural Cooperatives (JA) group have also begun to check and manage the production processes of individual farmers. As a result, many producer groups have obliged farmers to submit management work reports as well as records of farming materials and agricultural chemicals used in the production processes. Production history must be recorded at all times in every phase of the production process, which creates a high volume of paperwork and consequently exerts a heavy burden on both farmers and producer groups that support farmers.

To meet these requirements, we considered the desirability of introducing a web system to support the production process management of agricultural products by leveraging Information and Communications Technology (ICT). From the beginning of this century, IT equipment such as the personal computer (PC) has become increasingly popular. According to the survey by Park \& Mishra (2003), $55 \%$ of farmers in the U.S. used PCs for work purposes in 2000. Batte (2005) reported that the PC utilization ratio of farmers in Ohio State in 2003 was 43\%. Conversely, 24.1\% of farmers used PCs for work in Japan in 2006 (Ministry of Agriculture, Forestry and Fisheries, 2006). It implies that the diffusion of PCs in agriculture was very slow in Japan. The 


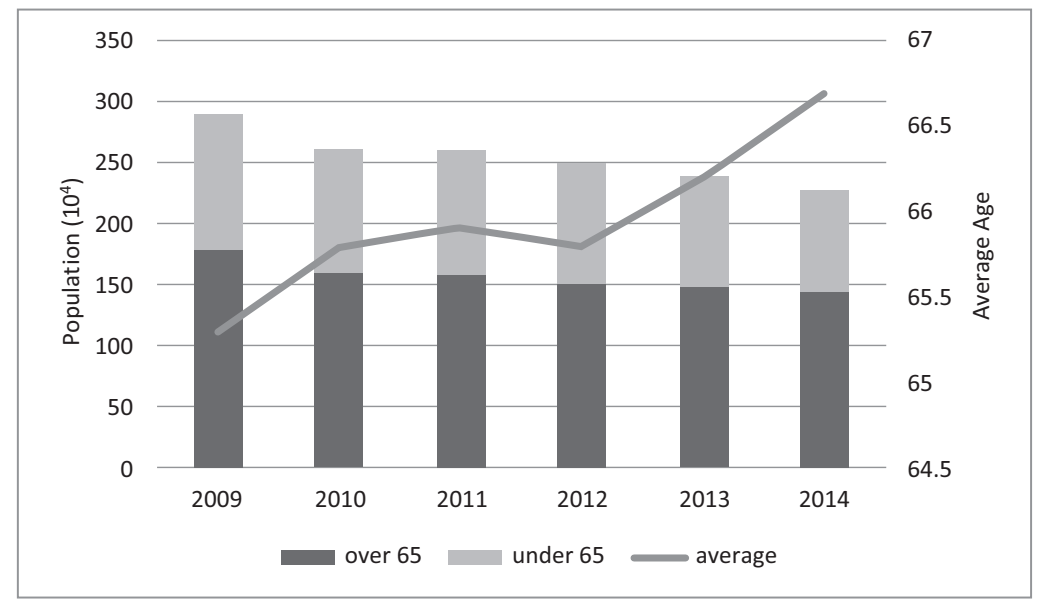

Fig. 1. Population and average age of farmers in Japan (Ministry of Agriculture, Forestry and Fisheries, 2015)

average age of the population engaged in agricultural practices in Japan is over 65 years (Fig. 1); the acceptance of ICT in agriculture is lower than that in other industries. Hence, it is important to upgrade the information management in the field of agriculture by utilizing ICT, though the fact that some farmers cannot use the ICT system should be considered. Since the early part of the century, several agricultural ICT systems were developed in Japan. For example, Nanseki et al. (2005) and Sugawara et al. (2006) developed a system for evaluating the suitability of using agricultural chemicals. Yoshida et al. (2009) and Hayashi et al. (2013) developed a field information management system equipped with the geographic information system (GIS) function. Each of these systems can support agricultural production process management by utilizing ICT, although no consideration is given to users who are unable to use IT equipment.

The development of ICT in recent years has been remarkable as new technologies have been introduced in succession and subsequently replaced older technologies. In other words, the easy implementation of a new system leads to the early obsolescence of existing technologies. As mentioned above, given the inadequate IT literacy of farmers in Japan, implementing frequent changes in system usage by introducing new technologies is not desirable. Thus, it is very important to design a system not only for stable operation but also for responding to the latest technologies.

In this study, I gave an account of the strategy for ICT system introduction in the field of agriculture. This study is based on my past studies (Itoh et al. 2014, Itoh 2016).

\section{System development}

After an incident occurred that involved the illegal use of agricultural chemicals, the government revised the
Agricultural Chemicals Regulation Law in 2002 and the Food Sanitation Act in 2003. Since the implementation of these Acts, farmers were required to record the management of the agricultural production process. Thus, we began to develop a system for managing agricultural production history information by leveraging ICT in 2003, and have been conducting demonstration experiments of the system in Hokkaido since 2004. This system is a web application called "The Management System for Agricultural Material and Production" (Fig. 2), and is accessible for both users and non-users of IT devices. By using this system, users can easily digitize and unify information on production processes. Non-IT device users can refer to a customized checking form and fill it out manually. The form is scanned to access the data, which is then automatically digitized by the optical character recognition (OCR) function (Fig. 3). Thus, everyone can use this system regardless of IT literacy level. Through the demonstration experiments, we confirmed that the system worked effectively in JA's practices. This system provides a standard checklist of items suitable for all crops, including a farming outline, work record, growth record, yield record, fertilizer usage record, and agricultural chemicals usage record. The system also allows users to record a wide range of additional information about the agricultural production process by making simple customizations. In addition, this system supports safe agricultural production by evaluating the appropriate application of agricultural chemicals and automatically calculating the amount of fertilizer by component.

\section{System improvements}

Technologies involving the Internet are improving rapidly and since 2005, a new trend called "Web 2.0" has been launched. New technological innovations, such as Ajax (in 2005 ) and cloud computing (in 2006), have rapidly made 


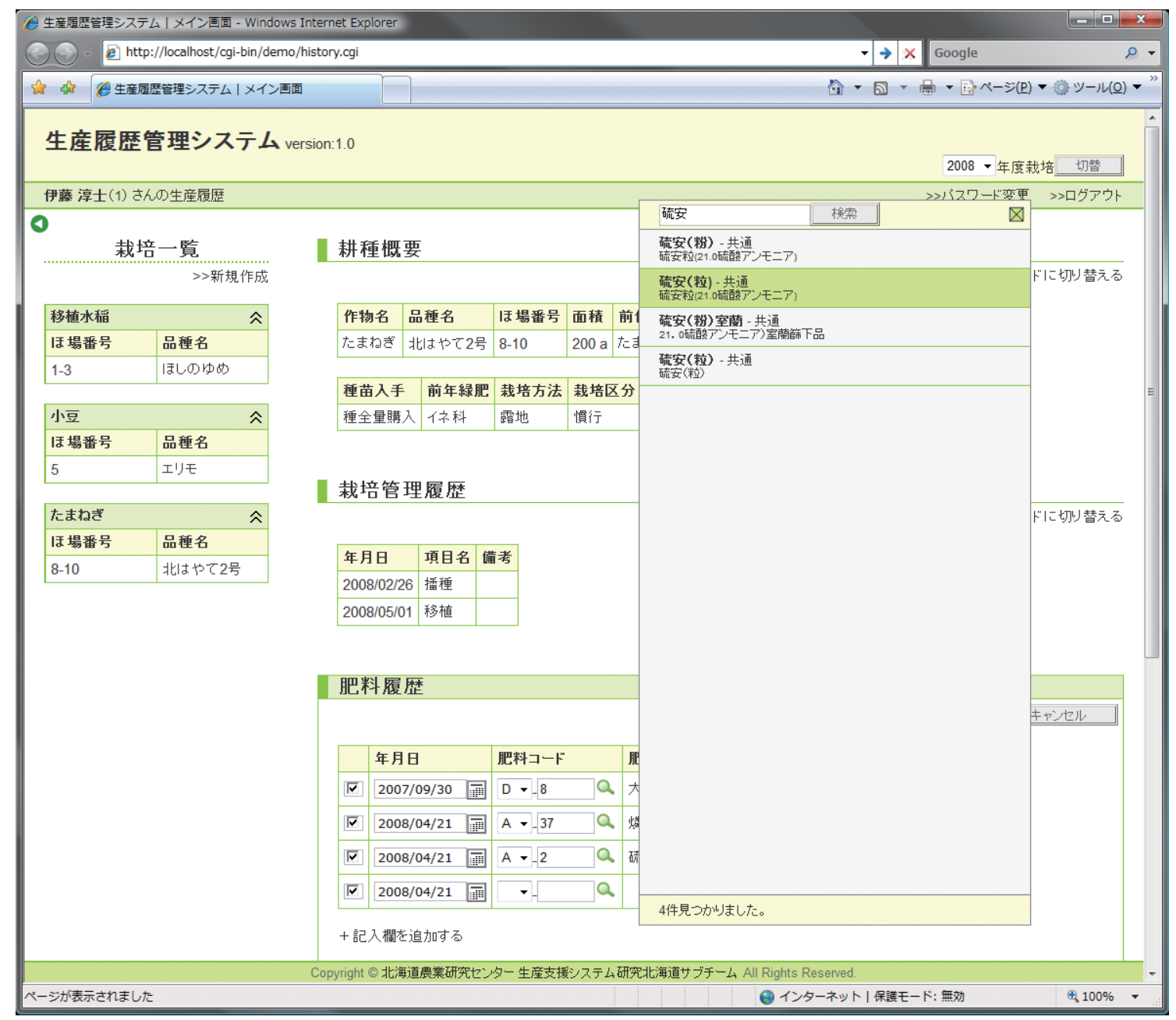

Fig. 2. Editing form on the browser (for IT device users)

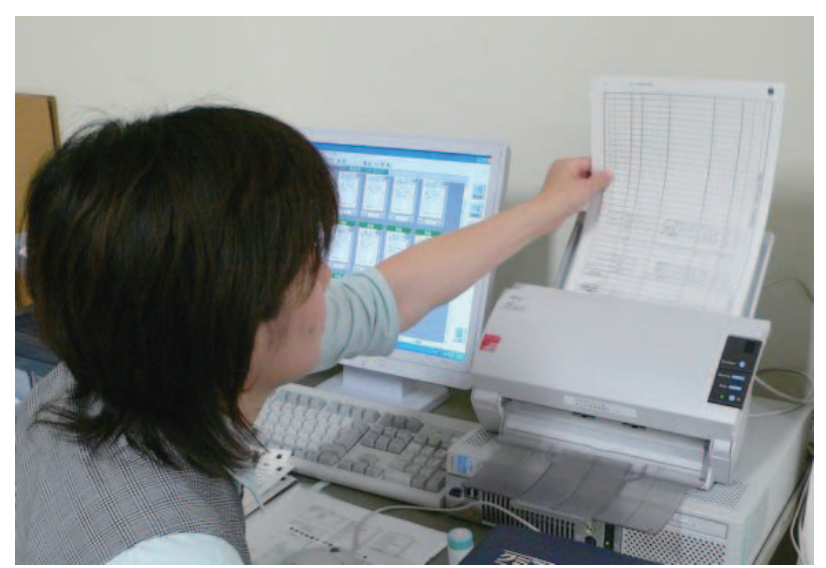

Fig. 3. Scanning a handwritten form

older web technologies obsolete. Moreover, Apple Inc. released the "iPhone" in 2007, resulting in the widespread popularity of such new terminals as smartphones and tablet PCs.

We therefore decided to restructure our previously developed system in order to increase system maintainability and scalability. We developed a new system for cloud services based on the "web application programming interface (Web API)" instead of the Common Gateway Interface (CGI), which we used in the previous system. We named the new system "apras" (short for agricultural production assistance system), and again returned to Hokkaido in 2013 for conducting demonstration experiments (Fig. 4). Table 1 shows the difference between the old and new systems. The introduction of "jQuery" (a standard library of JavaScript) and HTML5-compliant structure facilitated drastic improvements in the maintainability of "apras." In addition, the adoption of Cross-Origin Resource Sharing (CORS) for HTTP access control allows us to facilitate cooperation with external systems. Moreover, the introduction of the Web API method contributed to expanding the scalability of "apras." And given the improved scalability, we successfully developed the client software for smartphone usage in just three days. We also developed the API for the FaxOCR system for users who are not IT-literate. Accordingly, it was shown that "apras" could provide new functions very 


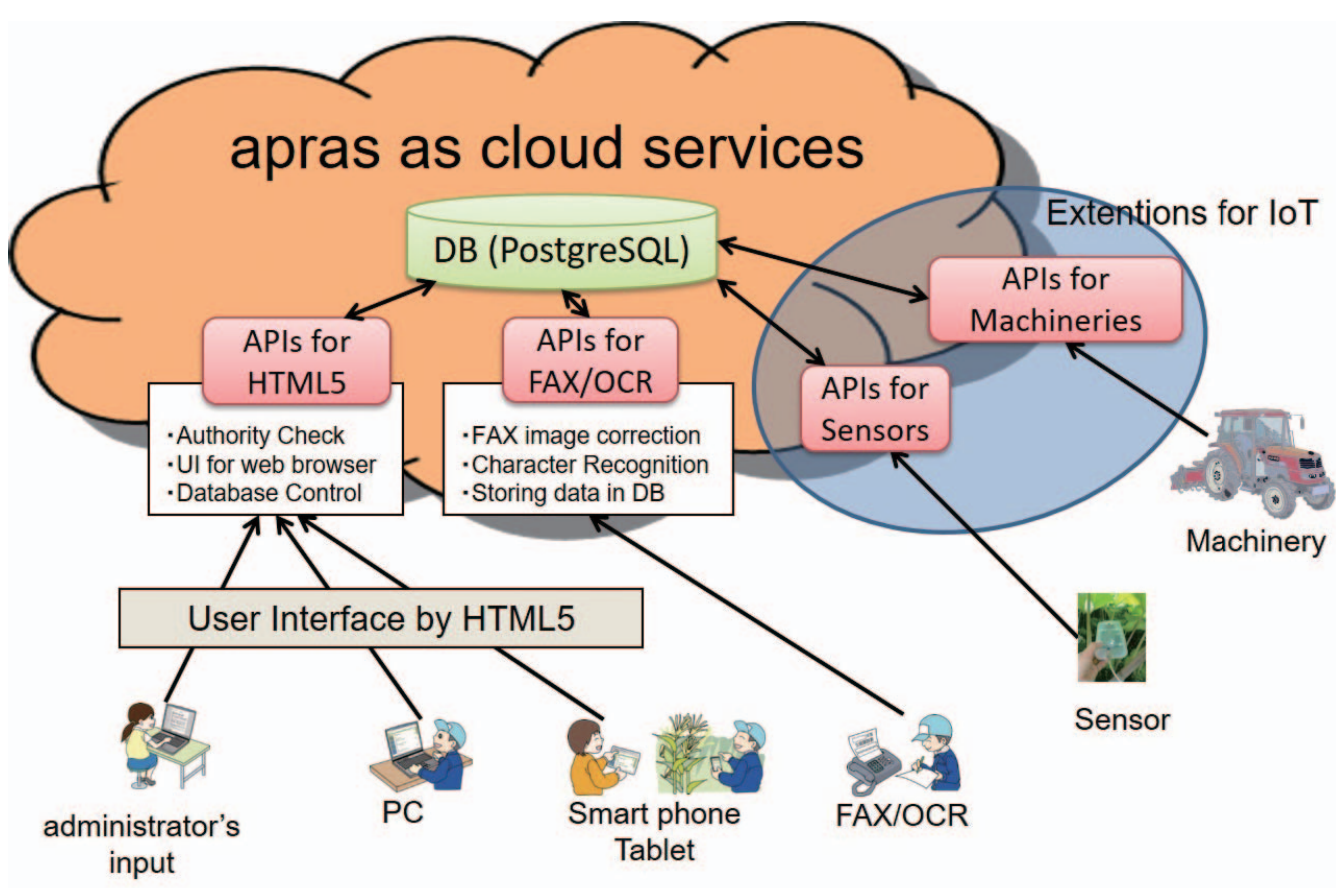

Fig. 4. Structure of "apras"

Table 1. Comparative table of old and new systems

\begin{tabular}{lll}
\hline \hline & \multicolumn{1}{c}{ New system ("apras") } & \multicolumn{1}{c}{ Old system } \\
\hline OS & Windows Server 2008 & Windows Server 2003 \\
Web server & Apache HTTP 2.2 & Apache HTTP 2.2 \\
Database & PostgreSQL 9.2 & SQLite \\
HTML version & HTML5 & HTML4.01 \\
CSS version & CSS3 & CSS2 \\
HTTP methods & GET, POST, PUT, DELETE & GET, POST \\
Data exchange format & JSON & custom format \\
CORS & compatible & incompatible \\
Interoperability & cooperation with other systems & difficult to implement \\
\hline
\end{tabular}

quickly to both the users and non-users of IT equipment. The scalability of "apras" would equip it to deal with the threats of new technologies and devices in the future, and possibly avoid the early obsolescence of the system.

\section{Results and discussion}

We have developed and improved the system for the management of agricultural production history. The system has been operated in Hokkaido by approximately 4,500 users without any trouble. One of the main factors that allowed us to operate the system without problems is that we provided appropriate functions for non-IT device users. This technology is significantly different from other agricultural ICT systems, and thus this system can be used by all users. In fact, an analysis of the logs of our system indicates that the demand for paper-based systems remains high. Actually, the number of non-PC users exceeds the number of PC users in many JAs (Itoh 2016). Accordingly, this suggests the effectiveness of using both the paper-based system and web-based system in the agricultural sector to address the need for effective information management in the field of agriculture.

Although the first system that we implemented was running well on-site, we decided to rebuild the system from scratch using the Web API technologies. The main purpose of rebuilding was to enhance the system's maintainability and scalability. Indeed, we were able to implement the system quickly for smartphones that were becoming popular at the time. And adoption of the Web API also enhanced the 
interoperability of the system.

\section{Future work and conclusion}

Humans are currently responsible for collecting production information, but in the near future, we can expect to gain much more information from sensor networks and robotic technologies. We implemented the mechanisms to aggregate a wide variety of agricultural information in "apras." Now we can assemble the sensor data on meteorology or a crop spectrum, and can also use the Controller Area Network (CAN) and global navigation satellite system (GNSS) for collecting data on agricultural machinery to "apras."

In the agricultural sector, we have to handle and manage a lot of information, such as on the weather, environment, crop growth, and soil conditions. Many systems and models dealing with such information have been developed in the past, although there is no mechanism to handle integrated information. For example, Kaloxylos et al. (2014) implemented a system for the integrated use of weather and crop growth data in the field. Currently, there are very few attempts to integrate agricultural information on the cloud using Web API. The information sharing in agriculture will pose an important challenge in the future.

We have shown that "apras" manages production history information effectively. We have also suggested the possibility that "apras" can work as a platform for a wide range of agricultural information, such as sensor data and agricultural machinery data. Studies on intensive collection methods of field data utilizing new technologies, such as the unmanned aerial vehicle (UAV), are currently in progress. In the near future, we will be able to easily collect substantial amounts of data, and thus believe that "apras" will progress significantly.

\section{References}

Batte, M. (2005) Changing computer use in agriculture: evidence from Ohio. Computers and Electronics in Agriculture, 47, $1-13$.
Hayashi, K., et al. (2013) Monitoring of the Operating Status of Agricultural Machinery and Information Management Technology using FARMS. Nogyo Kikai Gakkaishi (Journal of the Japanese Society of Agricultural Machinery), 75(4), 231-235 [In Japanese].

Itoh, A. (2016) Integrated-Utilization Methods for Diverse Information in Agricultural Production History Management Systems. PhD thesis, University of Tsukuba, Japan [In Japanese with English summary].

Itoh, A. et al. (2014) Development of Agricultural Production Process Management System "apras" as a cloud service. Nogyo joho kenkyu (Agricultural Information Research), 23(4), 154-164 [In Japanese with English summary].

Kaloxylos, A. et al. (2014) A cloud-based Farm Management System: Architecture and implementation. Computers and Electronics in Agriculture, 100, 168-179.

Ministry of Agriculture, Forestry and Fisheries (2002): Mutoroku Noyaku Mondai no Keii ni Tsuite. http://www.maff.go.jp/j/ nouyaku/n_sizai/mutoroku_keii.html [In Japanese].

Ministry of Agriculture, Forestry and Fisheries (2006): Noringyoka ni Okeru Pasokon Touno Riyoujoukyo Chousa. http://www.maff.go.jp/j/finding/mind/pdf/20060308cyosa. pdf [In Japanese].

Ministry of Agriculture, Forestry and Fisheries (2014): Heisei 26 Nendo Shokuryo Jikyuritu no Gaiyo. http://www.maff.go.jp/j/ zyukyu/zikyu_ritu/pdf/26gai.pdf [In Japanese].

Ministry of Agriculture, Forestry and Fisheries (2015): Nogyo Roudouryoku ni Kansuru Toukei. http://www.maff.go.jp/j/ tokei/sihyo/data/08.html [In Japanese].

Nanseki, T. et al. (2005) A navigation system for propriety pesticide use: design and implementation. Nogyo joho kenkyu (Agricultural Information Research), 14(3), 207-226 [In Japanese with English summary].

Park, T. \& Mishra, A. (2003) Internet Usage by Farmers: Evidence from a National Survey. Paper for presentation at the American Agricultural Economics Association Annual Meeting, Montreal, Canada.

Sugahara, K. et al. (2006) An Application to Judge and Record Appropriate Pesticide Uses Running on Mobile Phones. Nogyo joho kenkyu (Agricultural Information Research), 15(4), 381-393 [In Japanese with English summary].

Yoshida, T. et al. (2009) "Development of Planning and Management Support Software for Farm Work Using a Geographic Information System-Compatible Field Map", Nogyo joho kenkyu (Agricultural Information Research), 18(4), 187-198 [In Japanese with English summary]. 